\title{
Toxicosis-based aversions to visual cues in rats: A test of the Testa and Ternes hypothesis
}

\author{
BENNETT G. GALEF, JR., and ANDREW J. DALRYMPLE \\ McMaster University, Hamilton, Ontario L8S 4K1, Canada
}

\begin{abstract}
Testa and Ternes have proposed that the degree of spatial contiguity between a cue and a food object is an important determinant of the associability of that cue with toxicosis. We found, in accord with the Testa and Ternes hypothesis, that rats showed more profound illness-based aversions to the visual properties of food objects than to the visual properties of food bins or feeding chambers. This result has implications for the design of experiments undertaken to determine the relative associability of cues in different sensory modalities with toxicosis.
\end{abstract}

Testa and Ternes (1977, p. 239) have suggested that organisms will more readily form poison-based aversions to cues that covary in time and space with ingested objects than to cues that do not. On this model, one would expect, for example, that subjects form aversions to the visual properties of food objects more readily than to the visual properties of other objects in their environment.

The results of recent experiments in our laboratory indicate that rats pretrained to attend to the visual properties of their food rapidly acquire subsequent illness-based aversions to visually novel foods (Dalrymple \& Galef, in press). If Testa and Ternes are correct in asserting that the spatial relationship between a cue and a food object is a determinant of the ease with which that cue is associated with toxicosis, then pretraining rats' attention to exteroceptive cues spatially contiguous to food objects should be more efficacious in facilitating exteroceptive-cuetoxicosis conditioning than pretraining rats' attention to exteroceptive cues distal to food objects. For example, rats pretrained to attend to the visual properties of foods should learn to associate a visually novel food with toxicosis more readily than rats pretrained to attend to the visual properties of feeding chambers would learn to associate a visually novel feeding chamber with toxicosis.

This research was supported by grants from the National Science and Engineering Research Council of Canada and the McMaster University Research Board to B.G.G., Jr. We thank Paul Henne, Lynda Ashbourne, and Steven Wigmore for their technical assistance and the Parke-Davis Co. Ltd. of Brockville, Ontario, for providing us with many thousands of gelatin capsules without charge. The experiment reported here formed part of a dissertation submitted by the second author to the Faculty of Science of McMaster University in partial fulfillment of the requirements of the $\mathrm{PhD}$ degree. Material from this paper was presented at a meeting of the American Psychological Association, Montreal, September 1980. Requests for reprints should be sent to Bennett G. Galef, Jr., Department of Psychology, McMaster University, Hamilton, Ontario L8S 4K1, Canada.
In the present experiment, rats were pretrained to select palatable food, using as discriminanda: the visual properties of their food, the visual properties of the food bins in which food items were presented, or the visual properties of the feeding chambers in which foods were presented. Following discrimination pretraining, subjects in food-object, food-bin, and feeding-chamber groups, respectively, were allowed to eat: (1) a visually novel food, (2) from a visually novel food bin, or (3) in a visually novel feeding chamber. They were then poisoned. If rats are better able to learn illness-based aversions to food-related cues than to more diffuse cues, then one would expect subjects exposed to Condition 1 to exhibit stronger visual-cue-aversion learning than would subjects exposed to Condition 2 or Condition 3.

\section{METHOD}

\section{Subjects}

Subjects were 60 male Long-Evans rats weighing $150-200 \mathrm{~g}$ and obtained from Canadian Breeding Farms, St. Constant, Quebec.
Apparatus
The experiment was conducted in the two apparatuses illustrated in Figures $1 \mathrm{a}$ and $\mathrm{lb}$. The two items of equipment are identical in conception, the difference between them being that the "food bins" of the apparatus depicted in Figure 1a werc expanded in size to permit subject entry, thus making them the feeding cham- bers of the apparatus depicted in Figure $1 \mathrm{~b}$.
Both apparatuses were constructed of transparent Plexiglas, and each consisted of a startbox opening onto a goalbox via a guillotine door. Two openings in the wall of the goalbox opposite to the startbox door provided access to removable feeding areas (food bins in Apparatus 1a and feeding chambers in Apparatus 1b). In those portions of the experiment in which subjects had access to only a single feeding area (habituation, conditioning, and test- ing), one of the two openings was closed with a partition.
Food (powdered Purina Lab Chow packed into No. 2 gelatin capsules of varying color, $.35 \mathrm{~g} /$ capsule) was presented to subjects in feeding areas in the positions indicated in Figures $1 \mathrm{a}$ and $1 \mathrm{~b}$.
The experiment was conducted in a sound-attenuating room provided with background white noise of moderate intensity. 


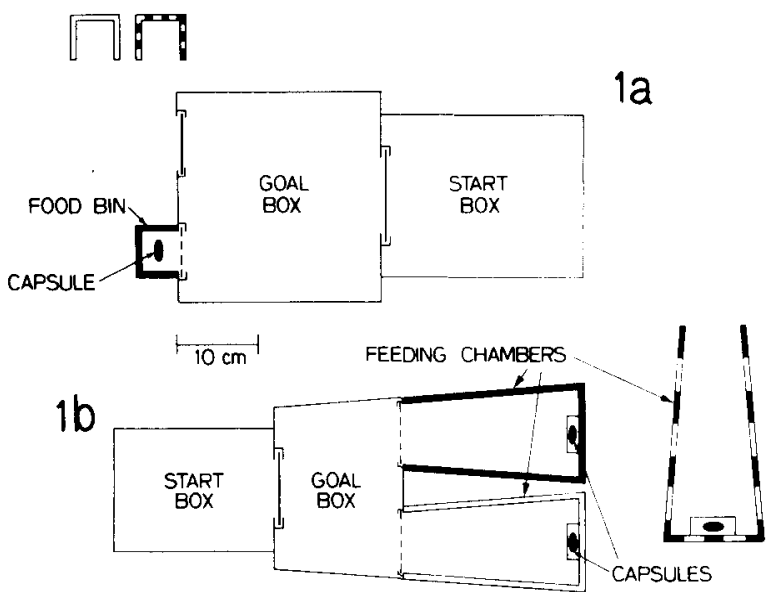

Figure 1. Overhead schematic of the two pieces of apparatus. The apparatus shown in Figure $1 \mathrm{a}$ is pictured with a single aperture in use (habituation, training, and testing phases) and that in Figure 1b with both apertures in use (discrimination pretraining phase).

\section{Procedure}

Throughout the experiment, each subject was housed individually, handled daily, and maintained with ad-lib access to water on a restricted feeding schedule (sufficient Purina Chow to establish and maintain body weight at $80 \%$ of that of controls with ad-lib access to food).

Habituation. For 7 days, all subjects were habituated to the test room and test apparatus in daily 100 -min sessions. On each day, subjects were placed in groups of 10 on a table in the experimental room and were moved in pairs to spend $20 \mathrm{~min}$ exploring the apparatus (either la or 1 b) in which they would be pretrained, conditioned, and tested.

On Day 8 of habituation, subjects were accustomed to eating encapsulated rations by the placement in each subject's cage, for $1 \mathrm{~h}$, of 10 No. 2 "white opaque" gelatin capsules (Parke-Davis Co. Ltd., Brockville, Ontario) filled with powdered Purina Lab Chow.

Subjects were further familiarized with experimental procedures on the following day, when each was trained for 10 trials in the apparatus in which it was to be pretrained, conditioned, and tested to run from the startbox to retrieve and eat Purina-Chow-filled "white opaque" capsules. Subjects failing to open capsules within $300 \mathrm{sec}$ of opening of the guillotine door on any two consecutive trials (six subjects) were excluded from the experiment.

Discriminative pretraining (Days 1 and 2). Each subject was assigned to one of the six groups and trained for 2 consecutive days (20 trials/day), using a noncorrection procedure, to choose between simultaneously presented pairs of capsules, one containing palatable Purina Lab Chow and the other unpalatable Purina Lab Chow (adulterated $4 \%$ by weight with quinine hydrochloride). Palatable and unpalatable capsules were placed equally often, in a pseudorandom sequence (Gellerman, 1933), to each subject's left and right as it entered the goalbox.

The visual discriminanda permitting selection of palatable capsules varied among groups. Subjects in the two capsule groups (C-C and C-E) were presented with "white opaque" palatable and "scarlet opaque" unpalatable capsules in identical white food bins. Subjects in the two food-bin groups (FB-C and FB-E) were presented with "white opaque" palatable and unpalatable capsules in, respectively, white and black food bins. Subjects in the two feeding-chamber groups (FC-C and FC-E) were presented with "white-opaque" palatable and unpalatable capsules in, respectively, white and black feeding chambers. Thus, subjects in all groups were required to attend to visual cues in selecting pal- atable foods for ingestion, but groups varied in the locus of those visual cues.

To initiate a trial, a subject was placed in the startbox of its apparatus and was left undisturbed for $30 \mathrm{sec}$. The guillotine door was then removed, permitting access to the goalbox. The subject was returned to the startbox for the next trial either $60 \mathrm{sec}$ after opening one of the capsules available to it or $300 \mathrm{sec}$ after opening of the guillotine door, whichever occurred first.

Each subject was pretrained until it achieved a criterion of 9 correct choices in 10 consecutive trials. A correct choice on a given trial was defined as opening and ingesting the contents of the palatable capsule prior to contacting the unpalatable capsule.

Conditioning (Days 3 and 4). Twenty-four hours following mastery of the discrimination pretraining task, half the subjects in each of the three discrimination pretraining conditions (C, FB, and $\mathrm{FC}$ ) were assigned randomly to an experimental condition and half to a control condition.

Subjects in all groups were presented for two trials on each conditioning day with a single capsule marked with a novel visual cue. The locus of the novel visual marker used during conditioning varied among groups in correspondence with the locus of the discriminanda to which members of each group had been pretrained to attend during discrimination pretraining. Thus, subjects in Groups C-E and C-C ate visually novel (half "white opaque" and half "scarlet opaque" capsules from a familiar white food bin, while subjects in Groups FB-E and FB-C ate familiar white capsules from a visually novel (black and white striped) food bin, and subjects in Groups FC-E and FC.C ate familiar white capsules from a visually novel (black and white striped) feeding chamber.

Subjects in Experimental groups (Groups C-E, FB-E, and FC-E) were injected intraperitoneally with $2 \mathrm{cc} / 100 \mathrm{~g}$ body weight of $.12 \mathrm{M} \mathrm{LiCl}$ solution $5 \mathrm{~min}$ after ingesting their second capsule on each training day. Subjects in control groups (Groups C-C, FB-C, and $\mathrm{FC}-\mathrm{C}$ ) were similarly injected $60 \mathrm{~min}$ after ingesting their second capsule on each training day.

Testing (Day 5). On the day of testing, we determined the latency of each subject in each group to open a capsule on each of 10 trials. As during the pretraining and conditioning phases of the experiment, on each test trial a subject was given $300 \mathrm{sec}$ in which to open the capsule. If it failed to open the capsule in that time, it was immediately returned to the startbox. If the subject did open the capsule within the alloted time, it was given an additional $60 \mathrm{sec}$ before it was returned to the startbox. All subjects were given $30 \mathrm{sec}$ in the startbox before initiation of the next trial. A single capsule was presented on each trial, in a single food bin ( $\mathrm{C}$ and $\mathrm{FB}$ groups) or feeding chamber ( $\mathrm{FC}$ groups) in pseudorandom order, equally often to the subject's left and right as it entered the goalbox (Gellerman, 1933).

During testing, each subject was presented with the same type of capsule and the same type of food bin or feeding chamber that it experienced during the conditioning phase of the experiment.

Experimental and control subjects within capsule, food-bin, and feeding-chamber groups were run blind so that neither the experimenter nor his assistant (who brought subjects from the colony room to the experimental room) knew whether any subject was assigned to experimental or control conditions until completion of the experiment.

\section{RESULTS}

The main results of the experiment are presented in Figure 2, which shows both group median and individual summed latencies of subjects in the six groups to open all 10 capsules on the day of testing. The data presented in Figure 2 have been transformed logarithmically to facilitate graphing.

Comparison of each experimental group with its respective control revealed that members of Experi- 


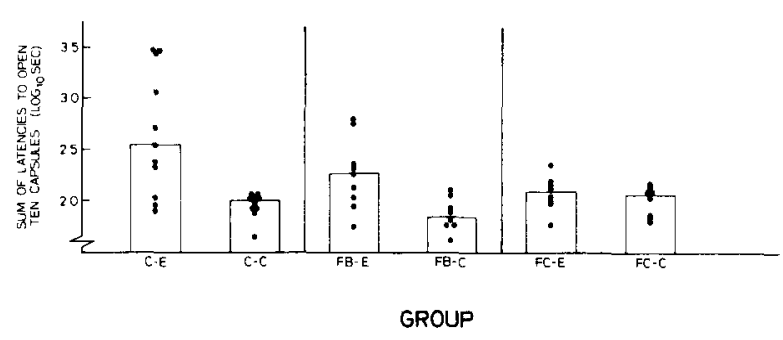

Figure 2. Group median and individual summed latencies to open all 10 capsules on the test day. See text for explanation of groups.

mental Groups FB-E and C-E took significantly longer to open all 10 capsules on the test day than did subjects in their respective control groups (median tests, capsule, and food-bin groups, both ps $=.05$ ); members of the experimental feeding-chamber group, on the other hand, did not differ from members of their control group on the summed latency measure (median test, n.s.).

Comparison of the three experimental groups (C-E, FB-E, and FC-E) with one another revealed an overall significant difference among groups (extension of the median test, .05 $>p>.02$ ) in capsuleopening latency. Members of Group C-E exhibited significantly greater latencies to open 10 test capsules than members of Group FB-E (median test, $p<.05$ ), and Groups FB-E and FC-E did not differ from one another.

Subjects in Experimental Groups C-E, FB-E, and FC-E, which differed in their latencies to open 10 capsules on the test day, did not differ in their rate of acquisition of the required discrimination during the discrimination pretraining phase of the experiment. The mean number of errors made by subjects in Groups C-E, FB-E, and FC-E prior to reaching criterion were, respectively: $5.4(\mathrm{SE}=.74), 7.2(\mathrm{SE}=1.65)$, and $5.0(\mathrm{SE}=.46)$ [extension of the median test, $\chi^{2}(2)=1$, n.s.].

\section{DISCUSSION}

The main results of the present experiment are consistent with the hypothesis that animals find it easier to associate toxicosis with the visual properties of food objects than with the visual properties of nonfood objects. As can be seen in Figure 2, the associability of a visual cue with toxicosis decreased as the visual cue was made more diffuse and less spatially focused on the food object itself.

It cannot be maintained that observed differences among experimental groups in strength of aversion learning resulted from differences in the general salience of capsules, food bins, and feeding chambers as visual discriminanda. Subjects were equally able to use each type of visual cue to distinguish palatable from unpalatable capsules during the discrimination pretraining phase of the experiment.

The main finding of the present experiment, that the strength of visual-cue-aversion learning depends on the relationship between the locus of exteroceptive cues and food objects, provides empirical support for Testa and Ternes' (1977) assertion of such a relationship. Our data also suggest that some caution must be exercised in interpreting the results of experiments intended to explore the relative associability of cues in different sensory modalities with toxicosis (e.g., Domjan \& Wilson, 1972; Garcia \& Koelling, 1966). Apparent differences in the associability with toxicosis of cues in various modalities may reflect, in part, effects of the spatial relationship between food objects and cues on the associability of those cues with toxicosis, rather than modality-specific differences in toxicosis associability. In particular, part of the difficulty that experimenters have encountered in conditioning a toxicosis-based aversion to visual cues in rats may have resulted from the diffuseness of the visual cues employed rather than from their modality.

\section{REFERENCES}

Dalrymple, A. J., \& Galef, B. G., Jr. Visual discrimination pretraining facilitates subsequent visual-cue-toxicosis conditioning in rats. Bulletin of the Psychonomic Society, in press.

Domjan, M., \& Wilson, N. E. Specificity of cue to consequence in aversion learning in the rat. Psychonomic Science, 1972, 26, 143-145.

Garcia, J., \& Koelling, R. A. Relation of cue to consequence in avoidance learning. Psychonomic Science, 1966, 4, 123-124.

Gellerman, L. W. Chance orders of alternating stimuli in visual discrimination experiments. Journal of Genetic Psychology, 1933, 42, 206-208.

Testa, T. J., \& Ternes, J. W. Specificity of conditioning mechanisms in the modification of food preferences. In L. M. Barker, M. R. Best, \& M. Domjan (Eds.), Learning mechanisms in food selection. Waco, Tex: Baylor University Press, 1977.

(Received for publication August 14, 1980; revision accepted October 22,1980 .) 